\section{Endoscopic treatment of a solitary hamartomatous polyp in the intrahepatic biliary duct}
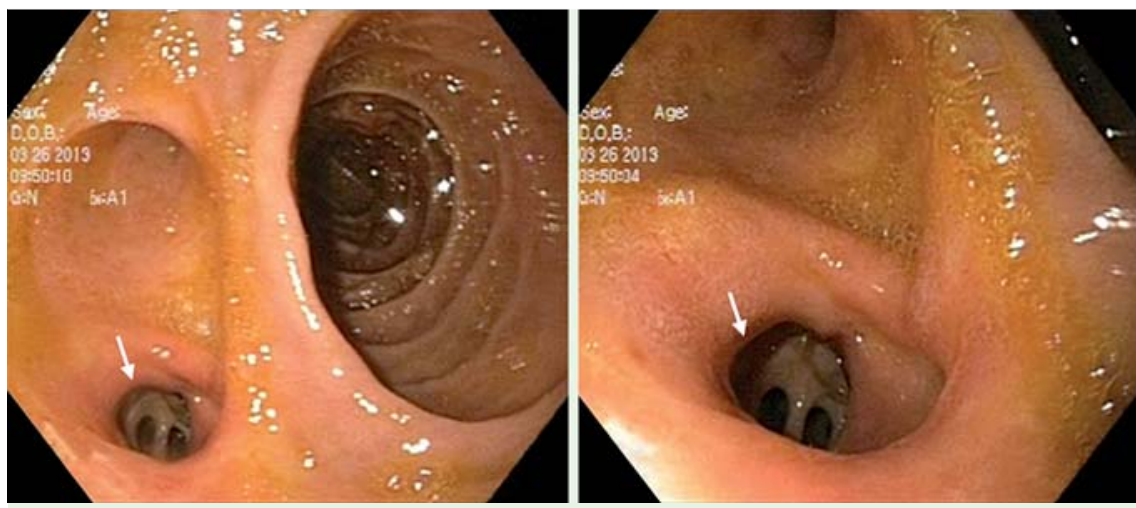

Fig. 1 Endoscopic finding of the surgical anastomosis and opening of a hepaticoduodenostomy (white arrow).
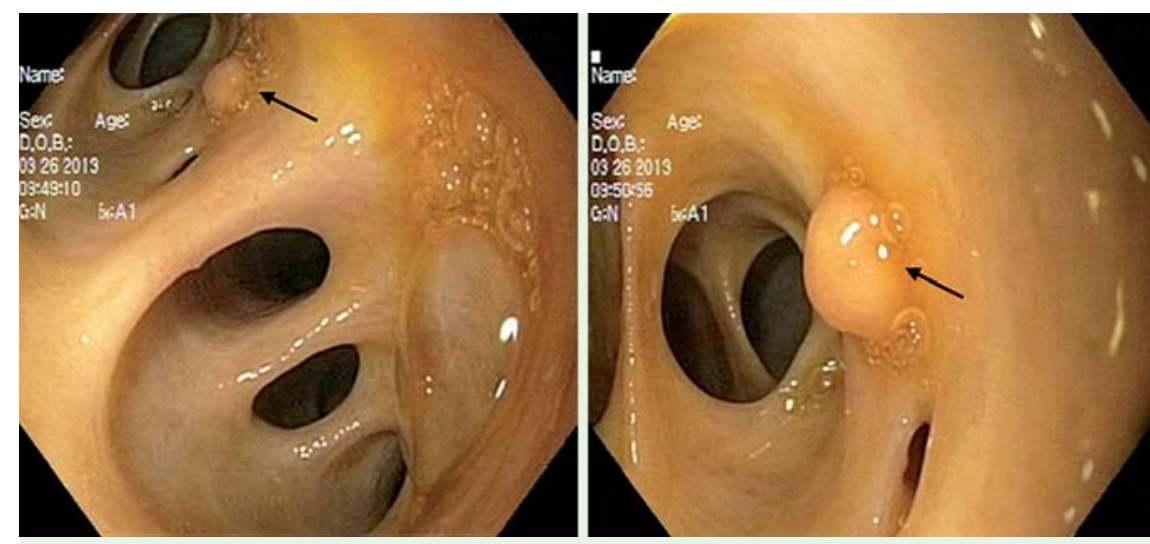

Fig. 2 Upper gastrointestinal endoscopy view showing a hamartomatous polyp (black arrow) in the intrahepatic biliary duct.
Hamartomatous polyps are usually found as part of Peutz-Jeghers Syndrome (PJS) and are uncommon, but occasionally a solitary hamartomatous polyp may develop in an otherwise healthy patient [1]. Hamartomatous polyps may appear commonly in the stomach, small bowel, or colon, with hamartomatous features on histology [2,3]. Polyps at extraintestinal sites such as the gallbladder, nose, uterus, urinary tract, and respiratory tract, are rarely found in patients with PJS [2 -4]. A recent case report described a sessile hamartomatous polyp in the second duodenal portion occupying the region of the ampulla of Vater [5]. To the best of our knowledge, hamartomatous polyps in the intrahepatic biliary duct have not been reported to date in the English literature. We describe the case of a solitary hamartomatous polyp in the intrahepatic biliary duct. A 54-year-old man presented with epigastric pain. On physical examination, there was epigastric tenderness but other system examinations were normal. Physical examination revealed no evidence of mucocutaneous pigmentation. No other members of his family had any abnormal pigmentation, intestinal polyposis, or notable medical problems. The patient had previously undergone cholecystectomy. His laboratory tests were normal.

A sonographic examination of the patient showed air in the intrahepatic biliary duct. The patient was referred for upper gastrointestinal endoscopy, during which a surgical anastomosis with the opening of a hepaticoduodenostomy was observed (৫ Fig.1). A polyp measuring $3 \mathrm{~mm}$ in
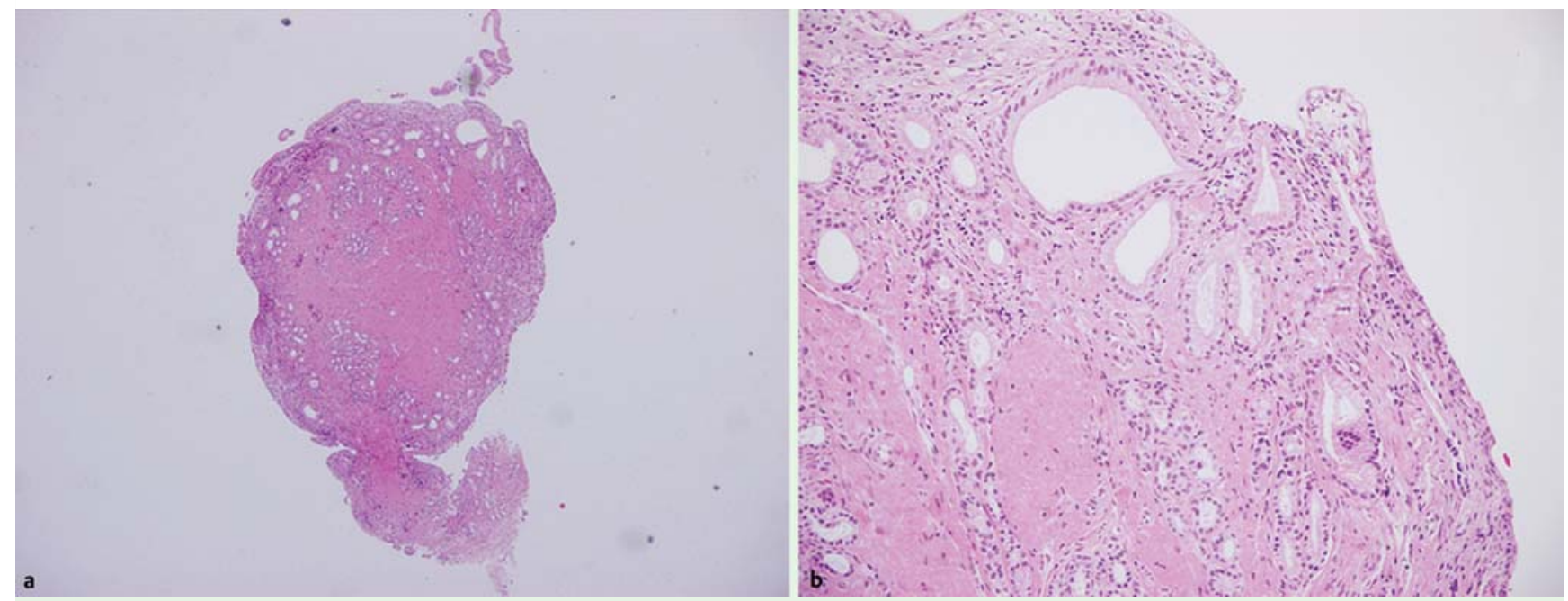

Fig. 3 Hamartomatous polyp in the intrahepatic biliary duct. a The section shows a polypoid structure consisting of a central fibrous stroma, surrounded by columnar epithelium; bile ducts with preservation of the lobular pattern are observed in the central fibrous stroma (hematoxylin and eosin, magnification $\times 40$ ). b Polypoid tissue: surface is lined by columnar-type epithelium and contains minimally dilated glands (hematoxylin and eosin, magnification $\times 400$ ). 
diameter in the intrahepatic biliary duct was also observed ( $\bullet$ Fig. 2 ). The polyp was completely removed by cold biopsy forceps. The histological findings of the polyp were indicative of hamartomatous polyp ( Fig.3).

To the best of our knowledge, this case is the first published report of a solitary hamartomatous polyp in the intrahepatic biliary duct.

Endoscopy_UCTN_Code_CCL_1AZ_2AC

\section{Competing interests: None}

T. Solakoglu1 ${ }^{1}$ E. Akin', S. H. O. Yavuz², O. Ersoy ${ }^{3}$

${ }^{1}$ Department of Gastroenterology, Ankara Ataturk Education and Research Hospital, Ankara, Turkey

${ }^{2}$ Department of Pathology, Ankara Ataturk Education and Research Hospital, Ankara, Turkey

${ }^{3}$ Department of Gastroenterology, Yildirim Beyazit University, Faculty of Medicine, Ankara, Turkey

\section{References}

1 Naitoh H, Sumiyoshi Y, Kumashiro R et al. A solitary Peutz-Jeghers type hamartomatous polyp in the duodenum - a case report. Jpn J Surg 1988; 18: 475-477

2 Tomlinson IP, Houlston RS. Peutz-Jeghers syndrome. J Med Genet 1997; 34: $1007-$ 1011

3 Aaltonen LA, Hamilton SR. World Health Organization. International Agency for Research on Cancer.. Pathology and genetics of tumours of the digestive system. Lyon; Oxford: IARC Press; Oxford University Press (distributor); 2000: 74-76

4 Vogel T, Schumacher V, Saleh A et al. Extraintestinal polyps in Peutz-Jeghers syndrome: presentation of four cases and review of the literature. Deutsche Peutz-Jeghers-Studiengruppe. Int J Colorectal Dis 2000; 15: 118 123

5 Pérez-Torres E, Fosado-Gayosso M, Gil-Rojas $N$ et al. Duodeno-biliary obstruction in Peutz-Jeghers syndrome. Cir Cir 2011; 79: $186-190$

\section{Bibliography}

Dol http://dx.doi.org/ 10.1055/s-0033-1344417 Endoscopy 2013; 45: E356-E357 (c) Georg Thieme Verlag KG Stuttgart · New York ISSN 0013-726X

\section{Corresponding author}

\section{O. Ersoy, MD}

Department of Gastroenterology Yildirim Beyazit University Faculty of Medicine Bilkent Ankara

Turkey 06800

Fax: +90-312-2912126

oersoy@yahoo.com.tr 